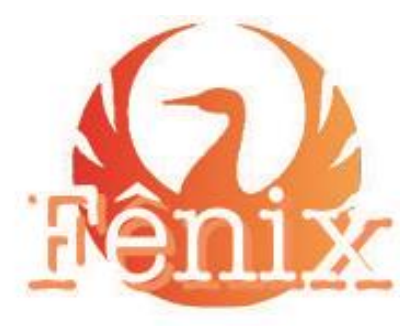

Revista de Histórin e Estudos Culturais

Janeiro-Junho de 2020

Vol. 17 Ano $17 n^{\circ} 1$

www.revistafenix.pro.br

ISSN 1807-6971

DOI: $10.35355 / 0000065$

\title{
DESCORTINANDO O PENSAMENTO DE PIERRE LÉVY
}

\section{UNVEILING PIERRE LÉVY'S THOUGHT}

\author{
Fernando Santos da Silva* \\ Universidade Presbiteriana Mackenzie - UPM \\ fercmo@gmail.com
}

Há algumas décadas, muito se tem refletido e discutido sobre a importância e as aplicabilidades da comunicação e sua simbiose com a tecnologia, principalmente em tempos de disseminação das redes de comunicação digital. Porém, o que vinha sendo debatido de forma parcimoniosa, numa tentativa de compreender de forma mais profunda, ganhou certa notoriedade nos últimos dias, visto a urgência de atender as demandas sociais.

Almejando reflexionar as reivindicações da sociedade sobre essa temática que se insere a obra: O Pensamento de Pierre Lévy - comunicação e tecnologia, de Guaracy Carlos da Silveira, publicada em 2019 pela Editora Appris. A presente composição, tem como escopo, apresentar a evolução das ideias de Pierre Lévy a uma recente geração de leitores que já nasceram imersos em um cenário de constantes mudanças tecnológicas, cotejando a pertinência do seu pensamento no contexto atual.

Para além de tal contribuição, Guaracy Carlos da Silveira que é um estudioso das interações entre Comunicação, Tecnologia, Educação e Cultura, vem dando significativas contribuições nos processos educacionais e planejamento estratégico, abordando não só as relações da Comunicação com a Tecnologia, mas também de forma considerável na área de jogos digitais aplicados a educação. Em trabalhos anteriores, empreendeu uma recapitulação da obra de Pierre Lévy, como forma de dirimir as confusões conceituais que se estabeleciam, decorrentes da publicação não cronológica 
de suas obras em português, além de estabelecer ligações entre o pensamento filosófico do autor e as áreas de Comunicação e Tecnologia.

Cabe consignar, inicialmente, que Pierre Lévy é um arguto pensador de temas complexos, ganhou proeminência no cenário nacional e internacional na década de noventa e após a virada do milênio com uma série de publicações questionando as relações entre sociedade, cultura e tecnologia. Com uma clareza ímpar, apontava as mudanças que estavam em gestação e convidava seu leitor a tomar ciência de tais transmutações e ser partícipe do processo, conduzindo-o com uma consciência planetária voltada para a melhoria de condição de vida de todos os cidadãos, alargando horizontes conceituais. De destaque, nos apresenta a relação de duplo vínculo entre mudanças tecnológicas e sociedade, onde o homem transforma a tecnologia ao mesmo tempo que é transformado por ela, fenômeno que demanda a convergência de múltiplos olhares e disciplinas, para ser adequadamente compreendido.

No Brasil, Pierre Lévy ganhou notoriedade com sua obra: As tecnologias da inteligência: o futuro do pensamento na era da informática (LÉVY, 1993), que culminou em seu "descobrimento" por conta do mercado editorial brasileiro, que resgatou suas obras e publicando-as de forma fragmentada entre cinco editoras. Processo árduo que, dificultou a compreensão da evolução do seu pensamento que vinha sendo articulado a cada nova obra. Pois, na perspectiva do leitor brasileiro, ele começa pela metade, volta para o início e depois retoma o fluxo de publicações subsequentes, ou seja, um verdadeiro emaranhado de ideias.

Nesse contexto, a gênese da obra ora apresentada, deixa evidente a força do contexto cultural das tecnologias. Se a quase três décadas era necessário um longo exercício no sentido de apresentar conceitos e desígnios que decorriam da interação da sociedade com a tecnologia, tal dinâmica na atualidade, torna-se desnecessária, visto que, a compreensão por parte da nova geração de leitores é intuitiva, sendo prática comum do dia a dia. Ao invés de apequenar o valor da obra, a ocorrência comprova o quão visionário foi Pierre Lévy, possibilitando um aprofundamento nos elementos conceituais de sua proposição. Embora tenha procurado evitar o caráter prescritivo em suas obras, não conseguiu se eximir ao estabelecer previsões do que estava por vir.

Avaliando tais sobreavisos, Guaracy Carlos da Silveira constata o alto índice de acertos, evidenciando a força das proposições filosóficas de Pierre Lévy, ressaltando 
a importância do posicionamento por parte dos pesquisadores, bem como, atuantes nesse processo de mudança.

O livro é prefaciado por Claudia Coelho Hardagh, pesquisadora da área de Ciências Sociais e Educação, cujos estudos estão alicerçados na relação entre Educação e Tecnologia e suas aplicabilidades. No decorrer do texto, chama a atenção para o trabalho desenvolvido pelo autor, ao tornar acessível a complexa trama abordada por Pierre Lévy. Expõe a relevância de resgatar e esclarecer conceitos muitas vezes utilizados de forma equivocada, principalmente na área da Educação, que por vezes, acabam por confundir dispositivos com técnica, ferramenta com conceito. Cessa sua participação, apontando que quando a sociedade contemporânea se assusta com as transformações tecnológicas e precisa se reorganizar a partir de uma nova concepção de ser humano, onde interação homem + máquina deve ser compreendida como uma ação social de modo a não haver dicotomia entre sociedade e tecnologia.

A obra O Pensamento de Pierre Lévy - comunicação e tecnologia, apresentase estruturada em cinco capítulos, que encaminham a uma leitura instigante ao colocar frente a frente e não em contraposição, conceitos e pesquisas que tecem uma rede de conhecimentos necessários para o entendimento das constantes transformações tecnológicas e culturais, pelas quais passamos.

O primeiro capítulo da obra "Tecnologias" caracteriza a compreensão de Pierre Lévy sobre as tecnologias, em especial aquelas que recebem o selo de "novas tecnologias" e o impacto destas na sociedade, dando destaque ao catalizador de mudanças: o computador. Dimensionando a interrelação história entre os seres humanos e os dispositivos tecnológicos num arco que vai desde a Idade da Pedra até a atualidade. Sugerindo que, o que temos é um longo processo contínuo cuja principal mudança é apenas a velocidade de implemento, ou seja, se antes as novidades tecnológicas eram implantadas na sociedade no curso de gerações, a velocidade dos processos atuais, culminou em uma única geração transitando por diferentes implementos, evidenciando que o conceito de "novas tecnologias" é apenas uma questão de perspectiva.

Embora aparentemente simples, tal conceito tem profundas implicações práticas, e aqui o autor vale-se de sua experiência na área de educação para apontar alguns "vícios" que decorrem desta posta, em especial no cenário brasileiro. Pois da dualidade inexistente entre novas e velhas tecnologias, decorrem uma valoração tecnocêntrica, onde o novo e sempre bom e o velho ruim, o que acaba por levar - no 
campo educacional - a uma adoção de tecnologias em processos educacionais sem o devido julgamento e principalmente, crítica.

Longe de propor uma posição neoludita, ou seja, não se opondo ao desenvolvimento tecnológico, o autor advoga que a formação de educadores e comunicadores, deveria abarcar um pensamento crítico das mídias e tecnológicas, de modo a permitir que, como agentes pensantes, professores e comunicadores apropriemse das tecnologias tendo ciência de seus benefícios, mas também, de suas limitações e possíveis malefícios, instigando uma visão menos ingênua e romântica.

"Comunicação" é o título atribuído ao segundo capítulo, que faz um cruzamento entre as proposições do campo da filosofia de Pierre Lévy e o campo disciplinar da Comunicação Social, fazendo um resgate de teorias comunicacionais (algumas delas com mais de 60 anos). Evidenciando as mudanças pelas quais atravessaram a sociedade, nos momento em que foram propostas até o contexto atual. De modo a explicitar a crescente complexidade e interligação dos meios de comunicação que passaram por um inaudito processo de evolução, demandando uma revisão de inúmeros postulados teóricos. Em especial, naquilo que o autor denomina de modelo clássico (linear, reducionista e determinista) das teorias da comunicação e uma nova perspectiva teórica mais aberta e multidisciplinar de fundo complexo. Fazendo uso de metáforas e exemplos biológicos, para fundamentar uma nova compreensão da comunicação social com bases sistêmicas.

O terceiro capítulo "A obra", notabiliza-se numa análise título a título das publicações de Pierre Lévy em língua portuguesa, respeitando a ordem cronológica de suas publicações originais em francês, objetivando apresentar suas principais ideias, evolução, mutação e, principalmente conexão. Considerando que se trata de uma análise de quase uma década de produção, articula-se num contexto de complexidade. Guaracy Carlos da Silveira, defende que o pensamento de Pierre Lévy não nasce pronto, mas, evolui conforme é vinculado em suas publicações.

Com efeito, o quarto capítulo "Ciberprocessos" objetiva apresentar o dimensionamento da relações entre: sociedade e tecnologia, marcada por um fluxo de codependência e de influência recíproca. Partindo do conceito de hipertexto, delineia as novas formas de comunicação que vão se articulando socialmente, fornecendo as bases teóricas e conceituais para futuras análises da sociedade em sua relação comunicação tecnologia. De particular valia aos pesquisadores da área de Educomunicação. 
Finalmente o quinto capítulo "Tecnologias da Inteligência" debruça-se sobre o conceito de ferramenta intelectual, que segundo o autor, é a maior e mais significativa contribuição de Pierre Lévy para os campos da Educação e Comunicação. Analisando como as definições e bases conceituais condicionam a percepção de determinadas ferramentas intelectuais, condicionam as formas como compreendemos os impactos destas tecnologias em nossas relações sociais e seus efeitos culturais.

Ao realizar, um resgate histórico do computador e a forma como é percebido e utilizado ao longo do tempo, revela o vício célebre que possuímos ao perceber a ferramenta com base em seus aspectos físicos e não em sua funcionalidade. Para tal, evoca a genialidade visionária de empreendedores como Bill Gates para compreender sua utilização em um contexto doméstico, e posteriormente de Steve Jobs para assimilar como esses dispositivos móveis, poderiam ancorar-se e desaparecer "na nuvem". Enxergando assim, o computador da perspectiva de seu suporte e não de sua função, é a cegueira de não compreender o que é uma ferramental intelectual. Posto de outra forma, chancela a capacidade intelectual de Pierre Lévy ao esclarecer esta dimensão.

Nesse ponto de vista, mapas, equações matemáticas, rotas mnemônicas e esquemas conceituais são tão ferramentas quanto o martelo, a pá e a enxada, pois ampliam o potencial humano. Se historicamente a evolução humana tem sido classificada com base no uso de ferramentais (Idade da Pedra Lascada, Idade da Pedra Polida e Idade dos Metais), estas tratam-se apenas de ferramentas físicas, sendo necessária sua expansão para uma compreensão das ferramentas intelectuais e seus impactos em nossa sociedade, tomando como exemplo a linguagem, o alfabeto e a escrita.

Por fim, o autor conclui seu livro concebendo uma síntese dos diversos focos e desenvolvimentos que tratou ao longo dos capítulos precedentes, apontando para a importância de revisar a obra de Pierre Lévy, considerado um escritor polêmico, prolixo, metafórico e muitas vezes hermético, condensando em um só volume, de forma sistematizada e didática. Outro ponto importante da obra é a ausência de deslumbramentos ou pessimismo, muito comuns a estudos que versam sobre a relação tecnologia e sociedade.

De forma bastante consciente, procura municiar o leitor a despeito de pontos para reflexão, convidando-o a ser participe desta linha de questionamentos e pesquisa, estimulando o raciocínio, a crítica e um posicionamento embasado. 
Disponível em: www.revistafenix.pro.br

E nesta dimensão bem específica que a obra se apresenta como um possibilidade de reflexionar sobre a interinidade da essencial cultural das áreas apresentadas. Afinal, se tradicionalmente as pesquisas relacionadas a Comunicação, Tecnologia e Sociedade, em especial no contexto brasileiro, evidenciam um caráter empírico e uma ausência de reflexão conceitual, a obra $O$ Pensamento de Pierre Lévy comunicação e tecnologia, cumpre sua proposta de integrar um seleto grupo referencial.

Em tempos de deslumbramentos face às virtudes de novas tecnologias e previsões apocalípticas sobre o fim dos empregos, controle absoluto do estado e alienação frente ao espetáculo, Guaracy Carlos da Silveira cumpre, portanto, a condição precípua estabelecida por Jürgen Habermas (2014), para quem se pronuncia sobre determinado tema: "saber do que se fala sempre ajuda", ao destacar o pensamento diferenciado de Pierre Lévy e sua tarefa de projetar uma nova e aprimorada versão da humanidade, ousa ao buscar tirar proveito da situação, sugerindo rumos possíveis, apresentando a perspectiva de uma sociedade alternativa, não apenas movida pelo lucro e pela aquisição material, nem massificada ou igualitária, não uma utopia, nem distopia, mas apenas, humana.

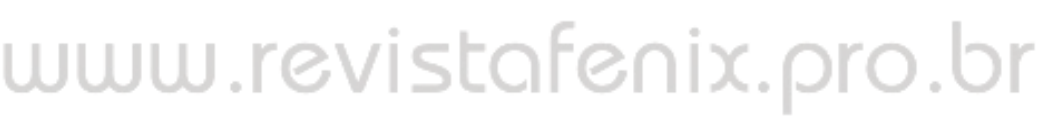

\section{REFERÊNCIAS BIBLIOGRÁFICAS}

HABERMAS, Jürgen. Conhecimentos e interesses. São Paulo: Ed. Unesp. Tradução de Luiz Repa. 2014.

LÉVY, Pierre. As tecnologias da Inteligência - O futuro do pensamento na era da informática. São Paulo. Editora 34. Tradução de Carlos Irineu da Costa. 1993.

SILVEIRA, Guaracy Carlos da. O Pensamento de Pierre Lévy - comunicação e tecnologia. 1 ed. Curitiba: Appris, 2019. 